\title{
Correlação entre a soroneutralização e teste imunoenzimático indireto para a detecção de anticorpos vacinais contra o vírus da Diarreia Viral Bovina (BVDV) e Herspesvírus Bovino Tipo-1 (BoHV-1)
}

Camila Costa Baccili[a]", Nathália Decaris ${ }^{[a]}$, Camila Cecilia Martin ${ }^{[a]}$, Karen Nascimento da Silva ${ }^{[a]}$, Fabrício Dias Tores ${ }^{[a]}$, Edviges Maristela Pituco[b], Cláudia Pestana Ribeiro ${ }^{[b]}$, Anibal Eugênio Vercesi Filho ${ }^{[c]}$, Viviani Gomes ${ }^{[a]}$

\footnotetext{
[a] Faculdade de Medicina Veterinária e Zootecnia, Universidade de São Paulo (USP), São Paulo, SP, Brasil

[b] Instituto Biológico, Laboratório de Viroses de Bovídeos, São Paulo, SP, Brasil

${ }^{[c]}$ Agência Paulista de Tecnologia dos Agronegócios, São Paulo, SP, Brasil
}

*Autor correspondente

e-mail: camila.rcosta@usp.br

\section{Resumo}

A vacinação é utilizada como estratégia para a prevenção das doenças reprodutivas infecciosas, entretanto, a ampla disponibilidade de produtos comerciais exige a averiguação da sua eficácia medida pela produção de anticorpos (ACs) específicos. Diante deste contexto, o objetivo desta pesquisa foi avaliar a correlação entre os testes de soroneutralização (SN) e imunoenzimático indireto (ELISA) na detecção de ACs produzidos em resposta às vacinas reprodutivas. Para tanto, foram selecionadas novilhas Holandesas $(n=35)$ soronegativas para BVDV e BoHV-1, com idade entre 15-24 meses. As fêmeas foram distribuídas em 4 grupos de acordo com o protocolo de vacinação: Vacina A ( $\mathrm{n}=9$ ), contendo o BVDV (Singer) e BoHV-1 (Los Angeles) em hidróxido de alumínio; Vacina B ( $\mathrm{n}=10$ ), contendo o BVDV-1, BVDV-2, BoHV-1 e BoHV-5 em adjuvante oleoso; Vacina C ( $=10)$, contendo o BVDV 1 (5960), BVDV 2 (53637), BoHV-1 (Cooper) em saponina, colesterol e amphigen; e controle não-vacinado $(n=6)$, - $5 \mathrm{~mL}$ de salina. Foram aplicadas 2 doses das vacinas $(5 \mathrm{~mL})$ por via subcutânea, com intervalo de 21 dias. Os ACs foram mensurados na vacinação (D0), booster (D21) e D42, por SN e ELISA (BVDV Total Ab Test e IBR Individual Ab Test IDEXX ${ }^{\circledR}$ ). Os títulos de Acs obtidos na SN foram transformados em dados qualitativos, considerando-se POS $\geq 16$ para BVDV e $\geq 32$ para BoHV-1. Todas as novilhas eram soronegativas no D0 e D21 para BVDV. No D42, as frequências de POS foram 55,5 e $77,7 \%$ para a vacina A; 0 e 0\% para a vacina B; e 20 e 30\% para a vacina C, respectivamente, na SN e ELISA. Em relação ao BoHV-1, as novilhas eram soronegativas no D0. No D21 detectou-se as frequências de 11,1 e $100 \%$ para a vacina A; 0 e 100\% para a vacina B; e 0 e 100\% para a vacina C na SN e Elisa, respectivamente. No D42, as frequências encontradas foram de 33 e 100\% para a vacina A; 0 e $100 \%$ para a vacina B; e 80 e $100 \%$ 
para a vacina C, na SN e ELISA, respectivamente. Apenas no D42 obteve-se correlação positiva moderada entre os testes para a detecção de ACs contra BVDV nas novilhas que receberam a vacina C $(\rho=0,646)$, e correlação fraca no grupo que recebeu a vacina $A(\rho=0,180)$. Conclui-se que os resultados entre ELISA e SN foram semelhantes para o BVDV porque a maioria das vacas não apresentou resposta após a vacinação. Em relação ao BoHV-1, observou-se maiores frequências de positivos utilizando-se o ELISA porque este teste detecta ACs totais e a SN, apenas os ACs neutralizantes. Os ACs neutralizantes são determinantes para a prevenção das viroses reprodutivas dos bovinos. A partir deste princípio pôde-se comprovar que apenas a vacina C induziu a produção de ACs protetores para o BoHV-1. 